\title{
Author Correction: Lysyl oxidase drives tumour progression by trapping EGF receptors at the cell surface
}

\author{
HaoRan Tang${ }^{1}$, Leo Leung², Grazia Saturno ${ }^{1}$, Amaya Viros ${ }^{1}$, Duncan Smith³, Gianpiero Di Leva1, \\ Eamonn Morrison', Dan Niculescu-Duvaz², Filipa Lopes², Louise Johnson², Nathalie Dhomen', \\ Caroline Springer ${ }^{2} \&$ Richard Marais ${ }^{1}$
}

Correction to: Nature Communications https:/doi.org/10.1038/ncomms14909, published online 18 April 2017.

This Article contains errors in Figs. 1, 2, 4, Supplementary Fig. 1c and Supplementary Fig. 3f, for which we apologise.

In Figs. 1c, 2c, 4j and Supplementary Fig. 1, samples from multiple biological replicates of each condition were run and probed; however, the blot images were assembled incorrectly such that different replicates were inadvertently selected as representative images for a subset of the antibodies used. The following blots depict a different biological replicate compared with the other blots within each experiment:

In Fig. 1c, the blot depicting surface EGFR levels in MDA-MB-231 cells and the blots depicting total EGFR and GAPDH levels in U87 cells.

In Fig. 2c, the blots depicting pAKT, total AKT and GAPDH levels.

In Fig. 4j, the blot depicting pY1068EGFR levels.

In Supplementary Fig. 1, the blots depicting pY1068EGFR levels in both MDA-MB-231 cells and U87 cells.

The correct versions of Figs. $1 c$ and $2 c, 4 j$ and Supplementary Fig. 1c are shown below as Figs. 1-4 respectively.

Furthermore, in Supplementary Fig. 3f, the blots probed with MATN2 and LOX antibodies were derived from samples run on separate gels, however only the GAPDH loading control for the MATN2 blot is depicted. The correct version of Supplementary Fig. 3f, with GAPDH loading controls for both the MATN2 and LOX blots, is shown below as Fig. 5.

These errors do not alter the original conclusions of the study. The error has not been corrected in the PDF or HTML versions of the Article.

Published online: 18 July 2019

\footnotetext{
${ }^{1}$ Molecular Oncology Group, Cancer Research UK Manchester Institute, University of Manchester, Manchester M20 4BX, UK. ${ }^{2}$ Gene and Oncogene Targeting Team, CRUK Cancer Therapeutics Unit, The Institute of Cancer Research, London SM2 5NG, UK. ${ }^{3}$ Biological Mass Spectrometry Unit, Cancer Research UK Manchester Institute, University of Manchester, Manchester M20 4BX, UK. Correspondence and requests for materials should be addressed to C.S. (email: caroline.springer@icr.ac.uk) or to R.M. (email: richard.marais@cruk.manchester.ac.uk)
} 

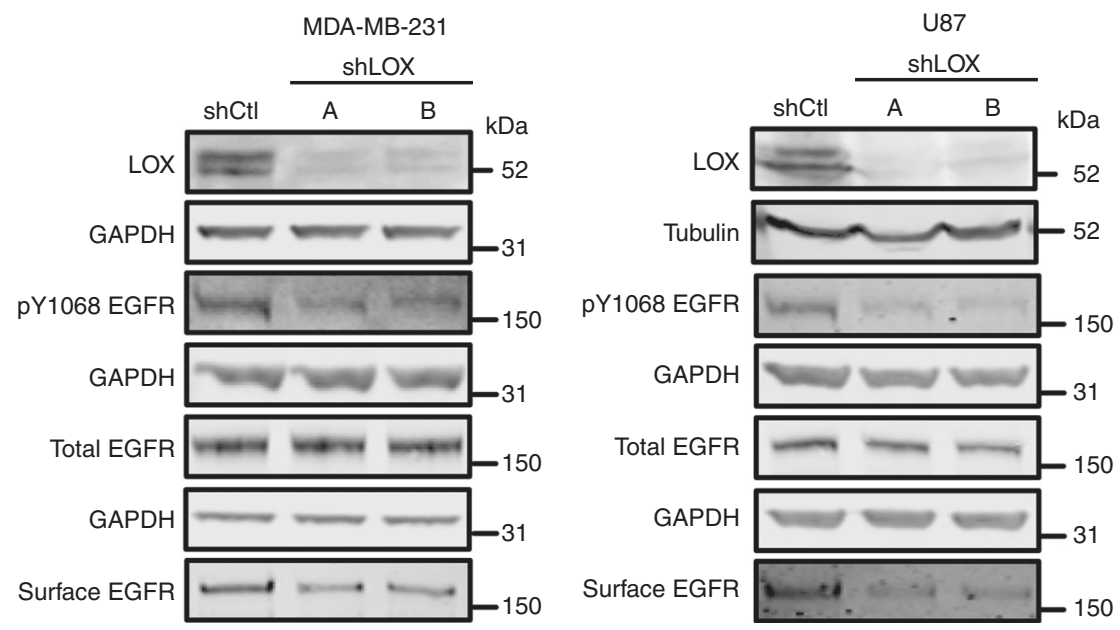

Fig. 1
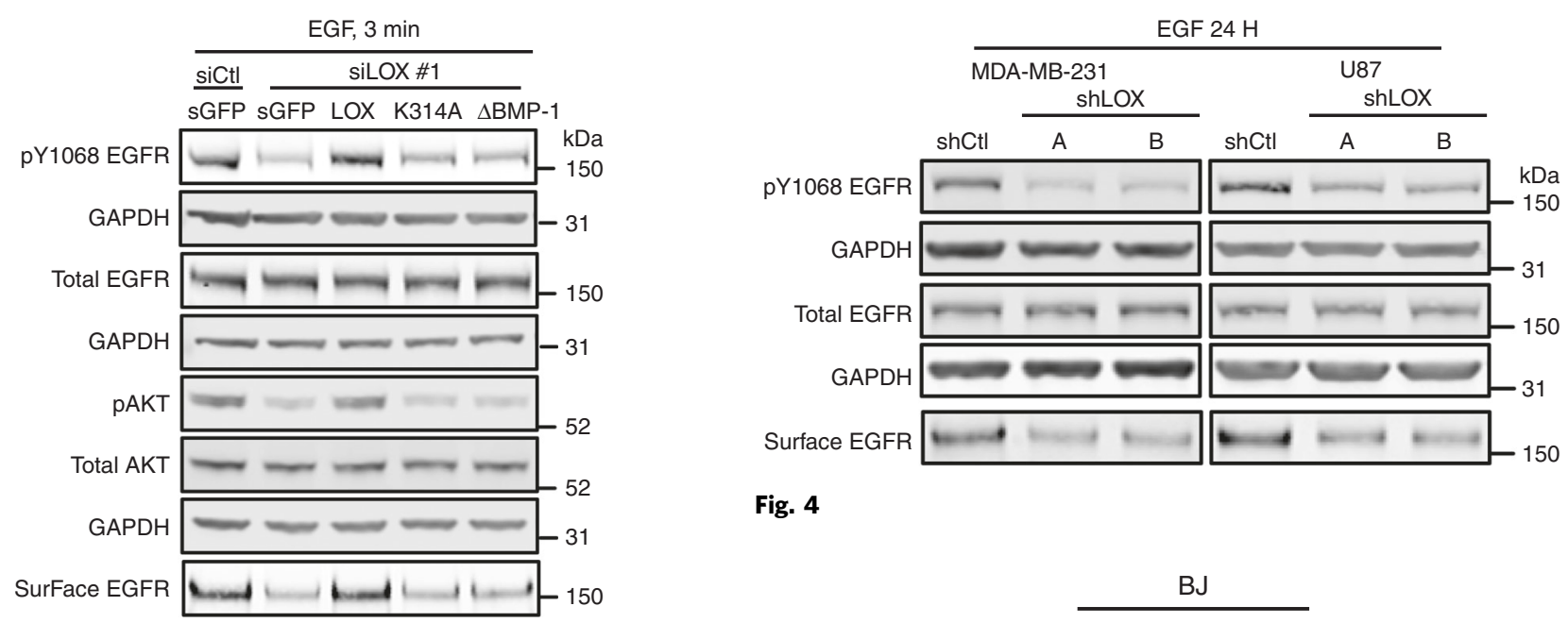

Fig. 4

Fig. 2
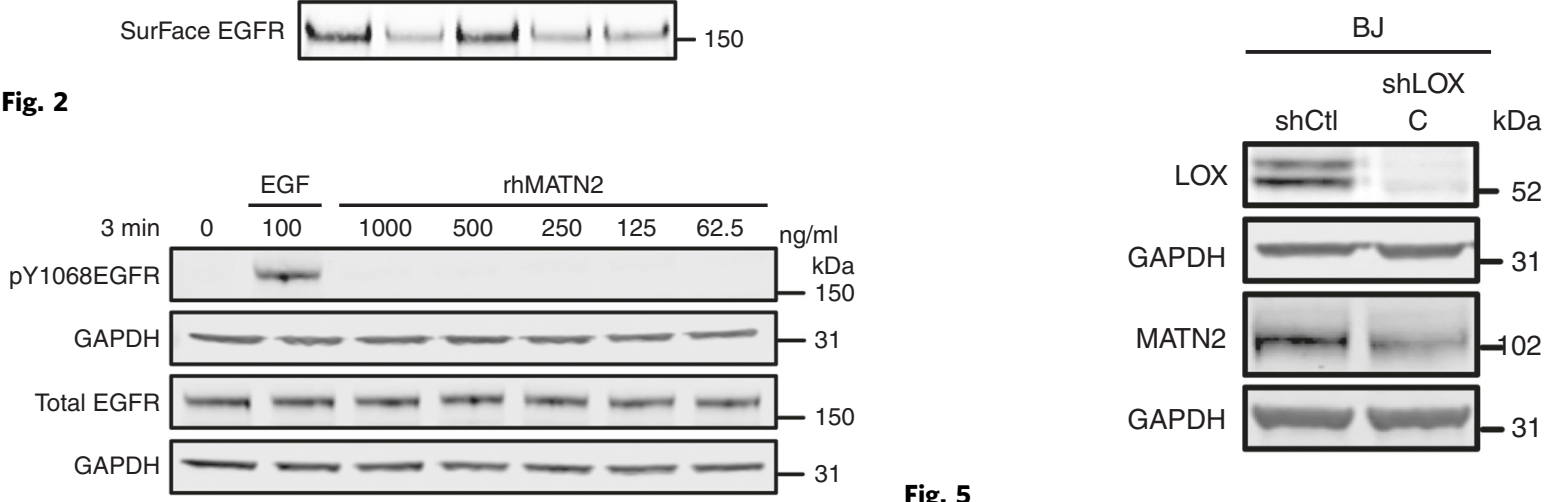

Fig. 3

Fig. 5

Fig.

(i) Open Access This article is licensed under a Creative Commons Attribution 4.0 International License, which permits use, sharing, adaptation, distribution and reproduction in any medium or format, as long as you give appropriate credit to the original author(s) and the source, provide a link to the Creative Commons license, and indicate if changes were made. The images or other third party material in this article are included in the article's Creative Commons license, unless indicated otherwise in a credit line to the material. If material is not included in the article's Creative Commons license and your intended use is not permitted by statutory regulation or exceeds the permitted use, you will need to obtain permission directly from the copyright holder. To view a copy of this license, visit http://creativecommons.org/licenses/by/4.0/.

๑ The Author(s) 2019 